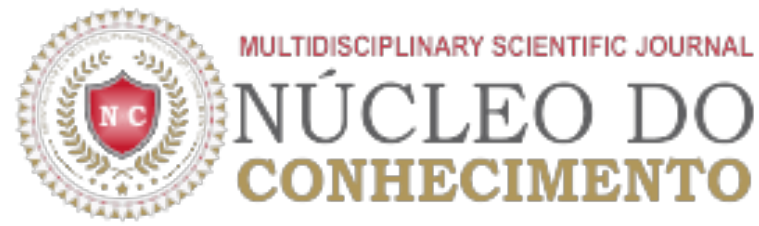

\section{Vigilância epidemiológica da Dengue: Educação Preventiva para surdos através da Pesquisa-Ação}

\author{
FREITAS, Heldimar Soares de $\stackrel{[1]}{ }$, VIEIRA, Silvio Santiago ${ }^{[2]}$, OLIVEIRA, Euzébio de ${ }^{[3]}$
}

FREITAS, Heldimar Soares de. VIEIRA, Silvio Santiago. OLIVEIRA, Euzébio. Vigilância epidemiológica da dengue: educação preventiva para surdos através da pesquisa-ação. Revista Científica Multidisciplinar Núcleo do Conhecimento. Ano 01, Ed 07, Vol. 04, pp. 60-74. Julho de 2016. ISSN: 2448-0959

\section{RESUMO}

A dengue é uma doença causada pelo mosquito Aedes aegypti, que acomete a sociedade e constitui um sério problema de saúde pública no Brasil e no mundo. O presente artigo visa compreender a pessoa com surdez sobre a necessidade de conhecer a dengue em Língua Brasileira de Sinais (Libras) no município de Marituba, localizado na região metropolitana de Belém, Pará-Brasil. Com intuito de sensibilizar a importância do tema proposto para o surdo, através de palestra conscientizando o mesmo com assunto traduzido/interpretado e também interpretado de uma língua fonte a língua portuguesa para uma língua alvo a Libras por meio visual usando a literatura surda como uma maneira de ensinar, fazendo com isso uma compreensão melhor para o tema em discussão e tendo como finalidade principal, levar essa informação que é de suma importância para a pessoa com surdez, possibilitando o surdo aprender sobre a dengue e porvindouro repassar seu aprendizado para a comunidade surda.

Palavras-chave: Vigilância. Epidemiologia. Dengue. Surdo. Educação.

\section{INTRODUÇÃO}

Desde o final do século passado, o mundo voltou seu olhar para os grupos especiais. Tais grupos representam aqueles indivíduos com deficiência, ou seja, pessoas com algum tipo de deficiência que os impedem total ou parcialmente de participar plenamente das atividades sociais regulares. A sociedade está repleta de exemplos de deficiências (CORRER, 2013).

Atualmente, os indivíduos com surdez são cada vez mais incentivados a serem incluídos definitivamente nas atividades e nos serviços que o sistema oferece a todos. Assim, novos modelos de inclusão são 
propostos e testados a todo tempo, como vagas específicas em escolas e concursos públicos. Rinaldo Correr (2003) afirma que "a comunidade deve aprender que, quando um de seus membros nasce com deficiências, todos os demais membros devem assumir juntos o compromisso de construir um ambiente inclusivo." As pessoas com surdez representam um sinal de que somos todos diferentes, e que essa diferença, antes de ser algo negativo, pode nos levar a termos atitudes mais tolerantes com tais dificuldades.

Assim sendo, o Sistema de Saúde Pública, não pode abrir mão de se adequar às necessidades dessa clientela, para isso é necessário um amplo esclarecimento para a pessoa surda sobre os locais onde os insetos usam como criadouros, afim de que cada pessoa possa contribuir mais ativamente na ação, promoção e manutenção da sua saúde e da pessoa surda e/ou ouvinte (AGUIAR, 1998).

Portanto é necessário empenhar-se como um alerta contra um possível surto de dengue, pois embora a sociedade tenha preocupação com a doença, ainda há muito a se fazer, principalmente em municípios que apresentam um sistema de coleta de lixo inadequado e falta de saneamento básico (DONALISIO; GLASSER, 2002).

Cotidianamente nos veículos de comunicações, estão circulando informações que expressam inúmeros episódios, que são considerados de grande importância para a pessoa surda e ouvinte. Dentre os fatos que são mais tratados pelos meios de comunicação social, estão àqueles voltados para os problemas na área da saúde pública, principalmente na atualidade, podemos citar a dengue. Desde os tempos antigos, as sociedades tinham interesse em estabelecer relações entre os fatores ambientais e a saúde, para prevenir a ocorrência e a disseminação de novos casos de doenças como é o caso da dengue (AGUIAR, 1998).

Sendo assim, a presente pesquisa teve como objetivo sensibilizar a pessoa com surdez para o tema que está na mídia e que é de extrema importância para o seu letramento resgatando assim um dever cidadão multiplicador da comunidade surda.

No primeiro momento buscou-se proporcionar para esses indivíduos o mesmo esclarecimento da doença e do vetor causador o Aedes aegypti, disponíveis as demais pessoas.

No segundo momento mostrou a forma do uso de tradução da língua Portuguesa para a Língua Brasileira de Sinais (Libras) com intuito de interpretar o assunto abordado para melhor compreensão da pessoa com surdez.

No terceiro momento, proporcionou como se passou o tema dengue no município de Marituba-PA, através da literatura surda com palestra informativa usando produção de imagem (classificadores) para o entendimento do surdo.

\section{METODOLOGIA}

Para o desenvolvimento deste artigo, utilizou-se a abordagem qualitativa com enfoque na pesquisa ação, como diz que:

A metodologia da pesquisa-ação-participante articula, radicalmente, a produção de conhecimentos com ação educativa, isto é, por um lado investiga, produz conhecimentos sobre a realidade a ser estudada e, 
por outro lado, realiza concomitantemente um processo educativo para o enfretamento desta realidade. Outro fator importante a se lembrado que esse tipo de pesquisa engendra a pesquisa qualitativa. (TOZONIREIS, 2006, p. 7).

A pesquisa-ação - Compreendendo a dengue - foi realizada na escola Municipal Paulo Freire no município de Marituba, localizado na região metropolitana de Belém-Pará, onde utilizou-se materiais para melhor compreensão do tema como: Banners, panfletos e vídeo relacionado com o tema, onde a produção literária foi usada na modalidade palestra informativa sobre a dengue em Língua Portuguesa (L2) para a tradução/interpretação para a Libras (L1). Informando sobre a doença e os cuidados para a eliminação do inseto Aedes aegypti causador da dengue.

\section{RESULTADOS E DISCUSSÃO}

\subsection{COMPREENDENDO A DENGUE}

A dengue é uma doença com infecção não contagiosa causada por um vírus (BOSCHILIA, 2003). A instituição clínica reconheceu a doença a partir de 1779 (LOIOLA, 2000).

O Aedes aegypti é um vetor da dengue, e é uma espécie de mosquito originário da África, acredita-se que chegou ao continente americano juntamente com as grandes embarcações, trazendo os escravos na época das colonizações por volta do século XVI. E o vírus causador da doença é proveniente do continente Asiático, e só deu entrada na América depois (NEVES, 2003).

Sua etiologia se estabeleceu na década de 40, quando se desenvolveu técnicas de laboratórios adequadas para permitir o isolamento do vírus e sua porvindoura caracterização. Para Teixeira (1999), ao longo da história pode-se constatar que a incidência da epidemia está agrupada com a chegada de novos sorotipos introduzindo nessas áreas.

Existem 4 sorotipos do vírus da dengue, denominados de sorotipo 1, 2, 3 e 4. No ano de 1954, o vírus do sorotipo 2, foi isolado pela primeira vez na América, na ilha de Trinidad \& Tobago, mas o vírus da dengue só se intensificou após a década de 60. O sorotipo 1, apresentou sua aparição em 1977, na Jamaica, vindo provavelmente do continente africano. A partir de então os países da América do Sul, que estavam livres da dengue foram acometidos por uma epidemia causada por esse sorotipo. Já o sorotipo 2, vindo da Ásia, foi o responsável pelo primeiro surto de febre hemorrágica ocorrido fora dessa localidade (BRAGA; VALLE, 2007).

No ano 1981, houve diversas epidemias com a introdução do tipo 4 no continente americano acreditando ter vindo das ilhas do Pacifico. O sorotipo 3, que não era encontrado desde 1978, voltou a aparecer em 1994 nos países da Nicarágua e Panamá. E no ano de 1995 a dengue já era a mais importante doença viral transmitida por mosquito no mundo (BRAGA; VALLE, 2007).

No inicio da segunda metade do século XX, foi observado soro positividade para a doença na Amazônia, a primeira epidemia só foi registrada em 1982, em Roraima na cidade de Boa Vista, produzida pelo vírus do sorotipo 1 e 4. Também ocorreram casos de dengue na década de 1980, com surtos de dengue clássico nos estados do Rio de Janeiro, Alagoas, Ceará, Pernambuco, São Paulo, Bahia e Minas Gerais (TEIXEIRA et al., 1999). 
A epidemia de Boa Vista capital do Estado de Roraima, ocorrida em 1982, foi um marco na história médica do Brasil e mostrou a deficiência da vigilância do Aedes aegypti. Com isso, a epidemia só foi detectada quando a curva epidêmica estava em declínio e não sabia sequer a época que boa vista estava dominada pelo mosquito. Sabe-se que os sorotipos responsáveis por cerca de 11.000 casos de infecção foram o sorotipo 1 e o sorotipo 4 (FACACCIO, 2010).

No Estado do Pará dois pequenos surtos no sudoeste do estado foram reportados em 1995, nos municípios de Redenção e Rondon do Pará, cujo sorotipo 1 foi isolado. No Estado de Tocantins ocorreram epidemias todos os anos apresentando pessoas infectadas com a dengue do sorotipo 2 (LEÃO, 1997).

O Aedes aegypti é o principal transmissor também da febre amarela urbana e da dengue em todo mundo, veio da África para América durante a colonização e a escravidão, primeiramente disseminou em toda faixa tropical em vista ao seu peculiar modo de reprodução e hoje é considerado cosmopolita. As fêmeas realizam a oviposição na parede de qualquer recipiente, próximo ao nível de água (NEVES, 2003).

No Brasil o Aedes aegypti tem como criadouros preferenciais os mais variados recipientes de águas domiciliares e peridomiciliares: pneus sem uso, latas, garrafas, pratos com vasos de samambaia, caixas d'água descobertas, piscinas sem uso, entre outros (Figura 1). 


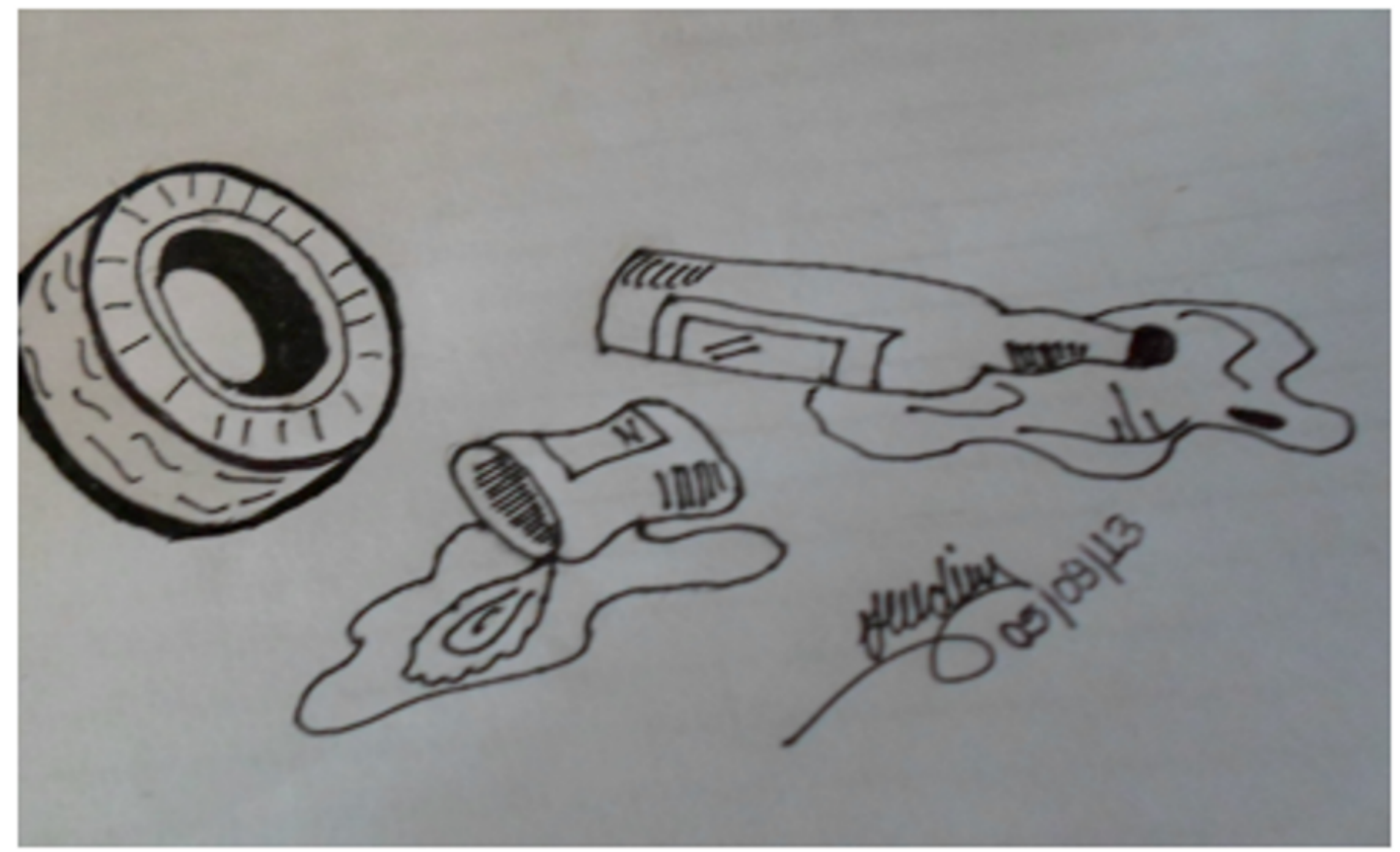

Figura 1: Criadouros para a proliferação do mosquito da dengue.

A figura 1 mostra alguns dos recipientes onde pode ocorrer a proliferação do inseto. A hematofagia, cópula e oviposição são diurnas. Acreditava-se que este mosquito possui a dispersão ativa e pequena, raramente excedendo os 200 metros, mas pesquisas recentes demonstram que a capacidade de vôo de fêmeas grávidas seja de 700m/dia esse vetor vive cerca de 20 dias (NEVES, 2003).

Exerce a hematofagia, tanto dentro como fora das casas, principalmente nos horários de 07 às 10 horas e depois de 16 às 19 horas. Tem predisposição de sugar o ser humano, principalmente nas pernas, mas também se alimenta de outros animais. Esse comportamento tem grande importância epidemiológica, pois uma fêmea infectada pode ter várias alimentações sanguíneas curtas em diferentes hospedeiros levando assim o vírus da dengue. Essas partículas virais são inoculadas através da saliva do inseto (NEVES, 2003).

No ciclo evolutivo do mosquito da dengue (Figura 2), os ovos são resistentes à dessecação, podendo permanecer por mais de um ano, após o contato com água, as larvas podem eclodir nos primeiros 15 minutos. A capacidade de dessecação dos ovos é considerada um dos obstáculos para o seu controle. Porque isso permite que esses ovos sejam transportados a grandes distâncias em ambientes seco. 


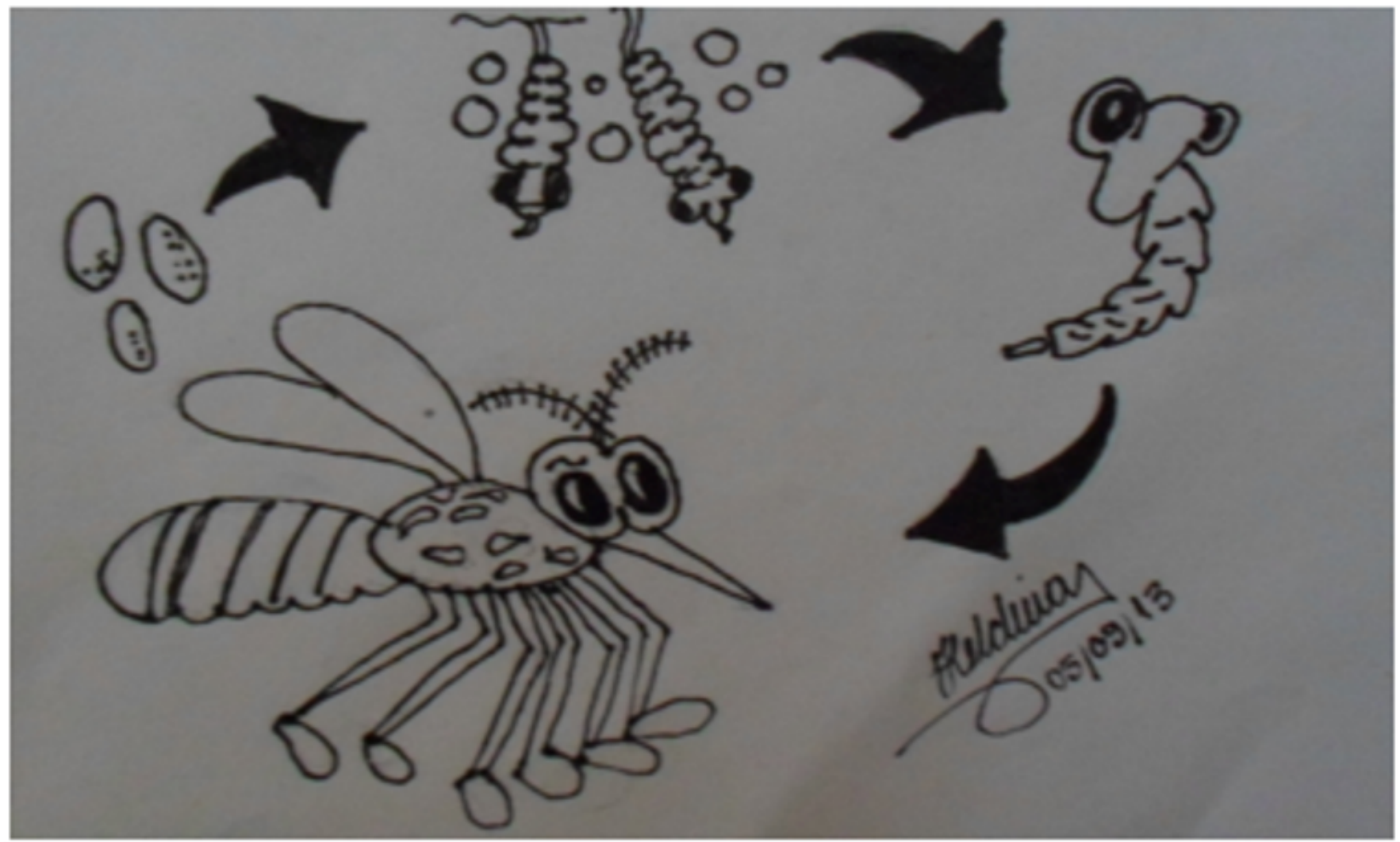

Figura 2: O ciclo evolutivo do mosquito da dengue.

A figura 2 ressalta o ciclo evolutivo do inseto vetor . Daí o aumento da população de Aedes aegypti durante o período de chuvas. $\mathrm{O}$ inseto pode ser reconhecido facilmente por apresentar cor geral marrom médio, apresentando uma nítida faixa curva, branca e preta de cada lado do tórax (mesonoto) e outra fina, reta, longitudinal, central, as quais formam a figura de uma lira (NEVES, 2003).

$\mathrm{O}$ vírus da dengue pertence ao grupo B dos arbovírus, família Flaviviridae, gênero Flavivirus. Esse tipo de gênero tem uma cobertura de 60 vírus, sendo que 21 já foram descritos como sendo patogênicos para o ser humano. Compreende 4 (quatro) sorotipos imunologicamente distintos: dengue 1, dengue 2 , dengue 3 e dengue 4. Após o tempo de incubação de 4 a 6 dias sendo que esse período pode variar também de no mínimo 3 e no máximo de 10 dias, o vírus do dengue encontra-se presente na corrente sanguínea dos pacientes em fase aguda da doença. A infecção por esses sorotipos no homem produz imunidade permanente contra uma nova infecção pelo sorotipo causador da infecção, porém ocorre apenas uma imunidade parcial contra os outros sorotipos, ou seja, uma imunidade temporária contra outros tipos (VERONESSI, 1991).

O Aedes aegypti é um vetor que funciona como um reservatório, pois uma vez infectado, os insetos vão permanecer ao longo de sua vida com o vírus. O Aedes mais importante por sua vez é o Aedes aegypti que é talvez o único vetor da dengue nas Américas (LEÃO, 1997).

No homem todos os sorotipos podem causar a febre clássica ou a forma hemorrágica da dengue com ou sem choque, não se conhece que um tipo é mais patogênico que o outro (BRASILEIRO, 2006). 
A infecção pelo o vírus do dengue causa uma doença cujo aspecto varia desde a forma inaparente ou assintomática, podendo haver uma evolução para o êxito letal (FUNASA, 2002).

A dengue, em sua clássica caracteriza-se por febre, dor muscular intensa, dores nas juntas, mancha vermelha na pele e pequenas manifestações hemorrágicas. Essa é a forma, mas branda da doença, cujo sintoma regride por volta de sete dias, a forma mais grave dengue hemorrágica, tem sintomas semelhantes a dengue clássica, mas no terceiro e quarto dias, começam a ocorrer sangramento interno, a pressão sanguínea diminui, os lábios ficam roxos, incidem dores abdominais entre outros sintomas levando a morte (AMABIS, 2006).

A dengue hemorrágica provavelmente ocorre quando um paciente, que já teve dengue é exposto a uma infecção por outro sorotipo do vírus. E com isso a influência mútua de fatores individuais, epidemiológicos e do próprio vírus pode promover essa condição de risco para o aparecimento dessa nova doença (AGUIAR, 1998).

O diagnóstico laboratorial específico tem principal importância nas áreas sem transmissão e com presença do inseto Aedes aegypti, nas localizações com transmissão estabelecida, mas com poucos casos. $\mathrm{O}$ resultado para confirmação em laboratório pode ser realizada por isolamento do vírus, testes sorológicos, detecção de genoma e antígenos virais (LEÃO, 1997).

Para a dengue clássica ainda não há tratamento específico, porém a medicação é apenas sintomática com o uso de analgésicos e antitérmicos, sendo que se deve evitar o uso dos salicilatos e dos anti-inflamatórios não hormonais, que usando pode aparecer manifestações hemorrágicas e acidose, o paciente deve ser orientado a ficar de repouso e iniciar uma hidratação oral (FUNASA, 2002).

No entanto, Aguiar (1998) nos remete ao fato de que devemos alertar que só a hidratação oral, na maioria das vezes não é suficiente, e que nos casos mais graves, se deve empregar a hidratação venosa, com o soro fisiológico e soro glicosado, até a diminuição do hematócrito, e a normalidade da diurese satisfatória e a estabilização da pressão arterial, por conseguinte, na FHD os pacientes devem ser observados cuidadosamente para a identificação dos primeiro sinais de (Figura 3). 


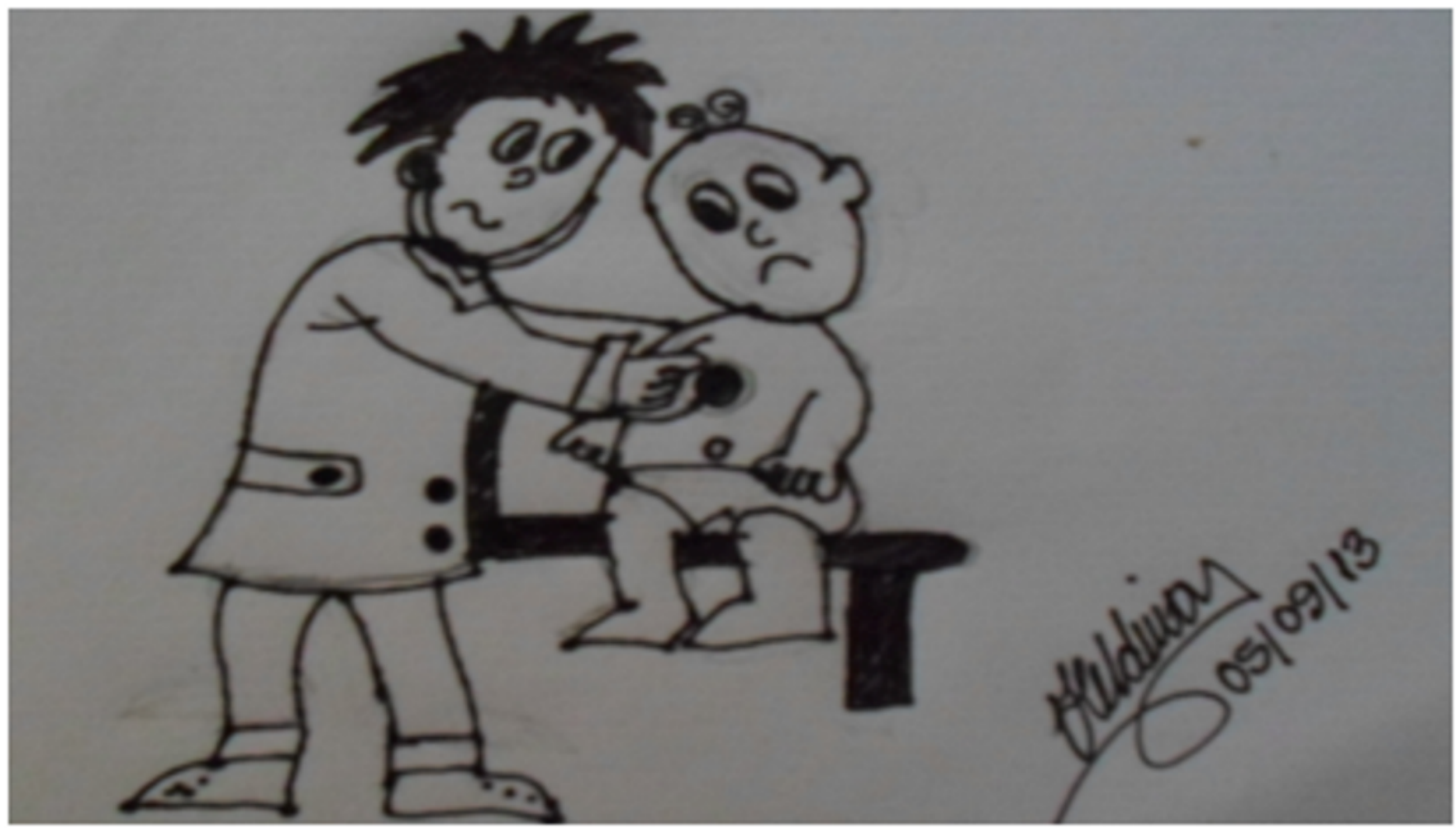

Figura 3: Avaliação médica sobre os sintomas da doença - dengue.

A figura 3 representa a avaliação médica sobre os sintomas da doença - dengue. O período mais crítico ocorrerá durante a transição da fase febril para afebril, que geralmente ocorre no período do terceiro dia da doença. Em casos com menor gravidade os vômitos dos pacientes ameaçam causar desidratação ou acidose, ou pode haver sinais de hemoconcentração, a sua reidratação pode ser feita em nível laboratorial (FUNASA, 2002).

O controle do vetor mais eficaz ainda é a prevenção, pois sua transmissão envolve o ciclo homem-insetohomem. O mosquito fêmea do Aedes aegypti, por ser hematófago se alimenta de sangue humano, e ao picar uma pessoa infectada, o vírus começa a se multiplicar no interior do inseto, por sua vez passa a contaminar outras pessoas. Não há transmissão por contato direto de uma pessoa contaminada com suas secreções, transmitir a doença para uma pessoa sadia, nem mesmo através de alimentos (AGUIAR, 1998).

O melhor método ainda mais eficaz para o combate a redução de incidência da dengue ainda consiste no controle do mosquito Aedes aegypti. Pretendendo assim eliminar os criadouros, uma vez que é um problema de saneamento doméstico. O grande desafio é sensibilizar a pessoa surda/ouvinte para o extermínio do inseto para poder controlar a dengue. (AMABYS, 2006)

\subsection{TRADUÇÃO/INTEPRETAÇÃO DA LÍNGUA PORTUGUESA (L2) PARA LIBRAS (L1)}

A aprendizagem da Língua portuguesa como L2 (L2- É a segunda língua que se fala. L1- Língua materna, ou seja, a primeira língua) para a pessoa surda deve levar em conta que é um processo diferente ao dos ouvintes, que aprendem a Língua Portuguesa em casa, no relacionamento familiar. A maior parte das pessoas surdas chega à escola sem uma língua adquirida. Entendendo-se que, por terem perda da audição, 
os mesmos compreendem a interagem com o mundo por meio de experiência visuais, manifestando sua cultura principalmente pelo uso da Língua Brasileira de Sinais- Libras, o Decreto Federal no 5.226, de 22 de dezembro de 2005, estabelece que os alunos surdos sejam submetidos a uma educação bilíngue, na qual a Língua Portuguesa, na modalidade escrita, é a segunda Língua (L2).

O fato de o processo ser concretizado através de línguas visuais-espaciais, garantindo que a faculdade de linguagem se desenvolva em crianças surdas, exige uma mudança nas formas como esse processo vem sendo tratado no contexto do ensino da língua de sinais como L1 (STOKOE, 1965, p. 02).

O autor comenta que a Libras como L1, desenvolve competência comunicativa da pessoa com surdez, para que o mesmo possa realizar uma concepção do mundo de forma ampliada e contextualizada. Toda língua humana - como a língua de sinais falada pelos surdos - atende aos critérios de criatividade, flexibilidade e versatilidade. Portanto, como língua que é, a Libras não é superficial, é uma língua natural, que emerge do seio da comunidade e se transforma ao longo do tempo, é dinâmica e com conteúdo absolutamente ilimitado. É possível falar qualquer coisa em Libras - desde que o sinalizante tenha fluência -, pois mesmo não havendo palavras comuns entre Libras e Língua Portuguesa, há possibilidade de transmissão (tradução/interpretação) do conceito da palavra.

No que tange essa possibilidade de transmissão do conceito da palavra, durante a pesquisa realizou-se uma palestra preventiva sobre a dengue. Levando-se em consideração que entre os participantes havia pessoas surdas, necessitou-se utilizar além da língua oral, a língua sinalizada: modalidades das línguas naturais com canal de emissão e recepção diferenciadas. Para melhor compreensão do que está tentandose explicar, ilustrou-se uma parte do texto da palestra sobre prevenção da dengue. Observa-se no quadro 1, onde aponta trecho da apresentação do trabalho realizado:

\section{Texto na Língua Portuguesa (L2)}

A dengue é uma doença que se não tratada pode levar a pessoa a morte, o causador é o mosquito "Aedes aegypti.
Texto em LIBRAS (LI). DOENÇA DENGUE CUIDAR-NÃO, PODER MORTE. DENGUE NOME A-E-D-E-S A-E-G-YP-T-I.

Quadro 1: Texto na Língua Portuguesa (L2) e Texto em LIBRAS (LI).

A frase na Língua Portuguesa foi traduzida para a Libras, para melhor compreensão do trabalho que foi desenvolvido durante a palestra preventiva. Ao mostrar esse processo de tradução, intencionou-se, fazer um pequeno despertar quanto às diferenças nas estruturas gramaticais dessas línguas.

De acordo com Quadros (2004):

Uma tradução sempre envolve uma língua escrita. Assim, poder-se-á ter uma tradução de uma língua de sinais para a língua escrita de uma língua falada, da língua escrita de sinais para a língua falada, da escrita da língua falada para a língua de sinais, da língua de sinais para a escrita da língua falada, da escrita da língua de sinais para a escrita da língua falada e da escrita da língua falada para a escrita da língua de sinais. A interpretação sempre envolve as línguas faladas/ sinalizadas, ou seja, nas modalidades oraisauditivas e visuais-espaciais. Assim, poder-se-á ter a interpretação da língua de sinais para a língua falada 
e vice-versa, da língua falada para a língua de sinais. Vale destacar que o termo tradutor é usado de forma mais generalizada e inclui o termo interpretação. (QUADROS, 2004, p. 9).

Importante se faz ressaltar que a interpretação ela pode se subjetiva, pois pode ser transmitida a informação de maneiras variadas, entre elas, por meio do uso de classificadores que é um tipo de morfema utilizado através da configuração de mãos e de alguma propriedade física o mesmo pode apresentar diferentes significados, embora apresente classificador e modo de expressar para o melhor entendimento do surdo (SUPALLA, 1982).

A temática "conhecendo a dengue", proposta neste artigo para o surdo, é uma tentativa de agrupar informações colhidas em diversas fontes bibliográficas e na prática, que generosamente desvenda-se, sob a forma de trocas de experiências, em que se destacam os surdos, conscientes de seu desempenho social na promoção da cultura surda, e os professores/pesquisadores ouvintes, que prestam informações na questão educacional do surdo.

É enfim uma contribuição de pessoas que há pouco tempo voltou o olhar para os surdos, em face de um chamado profissional, que logo se transformou em entusiasmo e desejo de conhecer mais e participar das discussões e ações em benefício da comunidade surda, na tarefa de construir uma sociedade multicultural e fraterna (SALLES, 2004).

Há um conjunto de práticas e eventos dentro da cultura surda que ativam as língua de sinais e suas formas de interação produzindo um letramento tanto individual como social que revelam dinâmicas próprias de atuar e interagir socialmente. Observando experiências lúdicas produzidas com a língua de sinais, percebendo a espontaneidade na criação textual que está presente nas associações de surdos apresentam uma determinada estrutura que se gerou culturalmente e está representada através das narrativas surdas.

Analisando também as experiências que ocorrem nos espaços escolares onde houve a possibilidade de encontro surdo-surdo também se evidencia uma metodologia que coloca em perspectiva uma forma própria de criação no que concerne aos aspectos de uma língua visual, imagética, de expressão corporal e de representação artísticas.

\subsection{LITERATURA SURDA}

A literatura surda tem uma proposta semelhante ao que diz respeito a literatura brasileira para ouvinte no que se refere a obra e autores.

A literatura surda tem uma lembrança diferente, próxima a culturas que transmitem suas histórias de presença e oral. Manifestando-se nas histórias narradas em sinais, mas o registro de histórias contadas no passado permanece na memória de algumas pessoas ou foram esquecidas. "Para refletir sobre literatura visual é preciso que pensemos que esta modalidade de texto surgiu no momento em que as pessoas surdas se apropriaram do saber sobre o poder de produção imagética de sua língua.” (FARIA, 2011, p. 169).

Nesse contexto a palestra sobre a dengue surge da necessidade de propiciar a comunidade surda, conhecimentos quanto à prevenção da dengue, e para tanto, aportou-se nos preceitos da literatura surda.

De acordo com Faria (2011): 
$\mathrm{Na}$ atualidade podemos considerar três tipos de produções literárias visuais. A primeira está relacionada a tradução para a língua de sinais dos textos literários escritos; a segunda é fruto de adaptações dos textos clássicos a realidade dos Surdos e por fim, o tipo que realmente representa o resgate da literatura Surda que é a produção de textos em prosa ou verso feitos por Surdos. (FARIA, 2011, p. 169).

Foi sobre o segundo aspecto que amparou-se esta pesquisa, por considerar que o conhecimento preventivo sobre a dengue, trata-se de um estudo clássico à sociedade de um modo geral, e nesse caso, da realidade dos surdos, inseridos nesse contexto.

Os surdos fazem parte de um grupo visual, de uma comunidade surda que pode se estender além da esfera nacional, no nível mundial. É uma comunidade que atravessa fronteiras. "De forma que eles fazem parte de uma sociedade nacional, com uma língua de sinais própria e com culturas partilhadas com pessoas ouvintes de seu país." (QUADROS; SUTTON-SPENCE, 2006).

Essa abrangência tende a ser maior, a partir do momento em que o ensino da escrita da língua de sinais começa a fazer parte do currículo escolar e circular em produções literárias.

[...] percebe-se que surdos contadores de histórias buscam o caminho da auto representação na luta pelo estabelecimento do que reconhecem como suas identidades, através da legitimidade de sua língua, de suas formas de narrar às histórias, de suas formas de existência, de suas formas de ler, traduzir, conceber e julgar os produtos culturais que consomem e que produzem. (KARNOPP, 2010, p. 172).

Além da importância dos registros na Libras, também é encontrado várias literaturas, presentes em associações de surdos, em escolas, em locais de encontro da comunidade surda.

Essas exposições são de grande importância para se entender a produção literária em sinais. Pessoas com surdez, convivendo com pessoas ouvintes, em seu local de trabalho ou com a sua família, se apropriam de meios visuais para abranger o conhecimento e se relacionar com as pessoas ouvintes (Figura 4). 


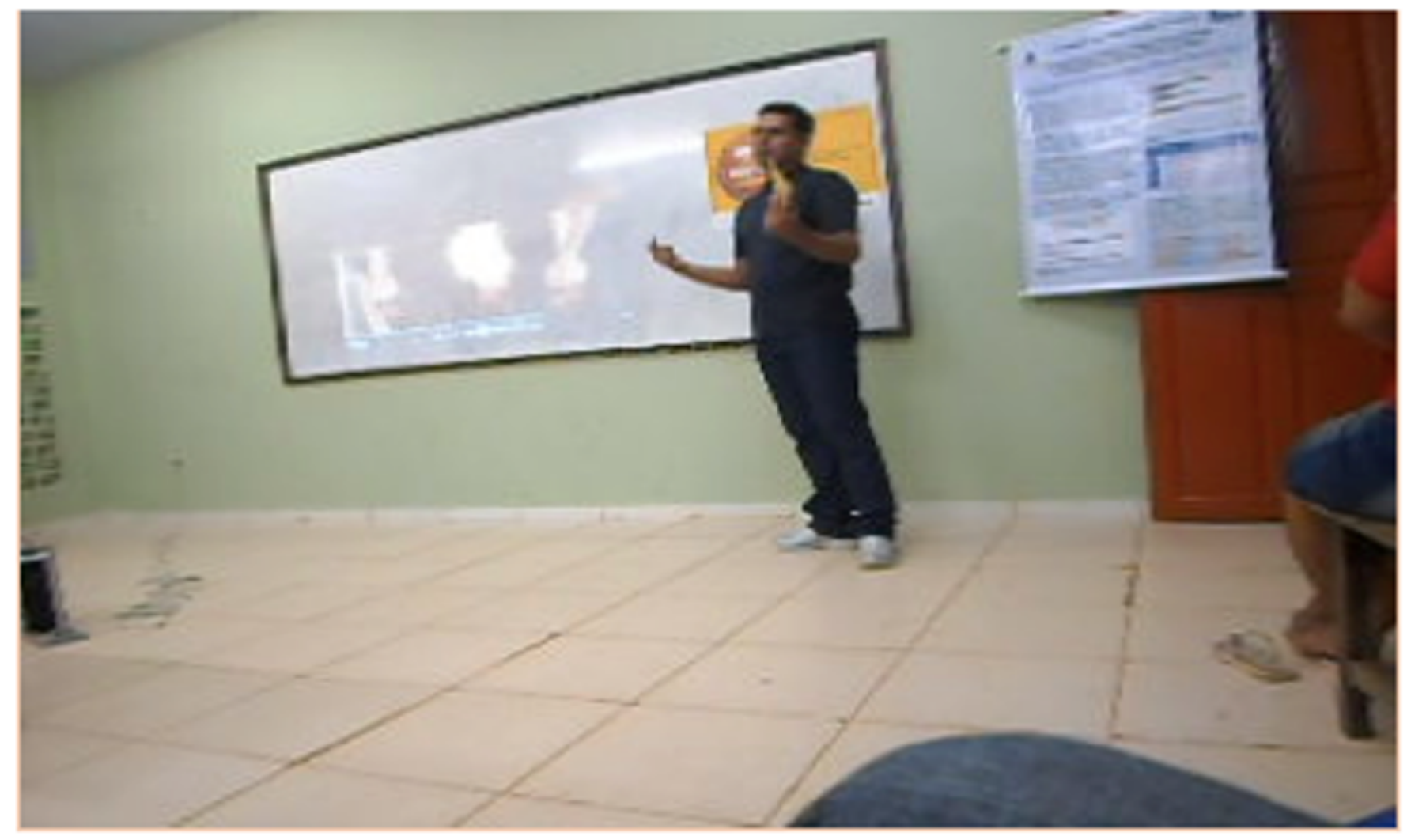

Figura 4: Apresentação do Tema dengue em libras.

A figura 4, exibe a interpretação do tema dengue em Libras com a interação pesquisador/palestrante e a comunidade (surdos e ouvintes), usando materiais audiovisuais para a melhor compreensão de todos.

Observou-se o interesse pelo tema em Libras, onde o sujeito surdo passou a ser inserido no contexto social, e teve uma participação atuante na buscar do saber, onde reforçou a necessidade da disciplina Libras nas escolas. As pessoas ouvintes que participaram da palestra mostraram interesse pelo assunto e pela língua de sinais. E o surdo ao compreender a dengue passa a fazer essa intermediação para a comunidade surda onde está inserido. Pois a cultura surda refere-se aos códigos próprios dos surdos, suas linguagens e organização. O surdo envolvido com a cultura surda identifica-se como participante (SKLIAR, 1998).

Contudo trazendo informações sobre a dengue dentro dessa cultura surda, o mesmo passa a ter sabedoria de conversar ou até mesmo informar com propriedade em libras sobre o tema e assim tornando-o agente multiplicador dessas informações para os demais surdos.

\section{CONSIDERAÇÕES FINAIS}

A palestra sobre a dengue para pessoa com surdez na escola Paulo Freire em Marituba na região metropolitana de Belém-Pará, vem ressaltar a acuidade da língua brasileira de sinais para atrelar a pessoa surda e ouvinte, aja vista que os alunos surdos conseguiram compreender a importância de conhecer sobre o mosquito e a doença, e passaram a incluir-se no tema com autonomia. As manifestações dos alunos ouvintes e professores sobre o interesse de aprender a libras para ter o contato direto com a pessoa surda 
só reforçaram mais a necessidade da buscar do conhecimento. A pessoa surda sabendo dessas informações voltadas a dengue, passa a serem multiplicadores sobre o tema, e leva para a sua comunidade (surda) a prevenção e o conhecimento da doença. Uma vez que é direito de todos terem essa informação.

\section{REFERÊNCIAS}

AGUIAR, Adriana Cavalcanti. Texto de Apoio Vigilância Epidemiológica. Editora: Fio Cruz, Rio de Janeiro, 1998.

AMABIS, José Mariano. Fundamentos da Biologia Moderna. Edição 4º Editora Moderna, São Paulo, 2006.

BOSCHILIA, Cleusa. Minidicionário, compacto de biologia. $2^{a}$ edição. Ed. Rideel. São Paulo, 2003.

BRAGA, Ima Aparecida; Valle, Denise. Aedes aegypti: histórico do controle no Brasil. 2007.

BRASIL. Ministério da Saúde. Fundação Nacional da Saúde, Dengue: Aspectos epidemiológicos, diagnóstico e tratamento, Brasília, 2002.

BRASILEIRO, Geraldo Filho. Patologia. Edição 7ª, Ed. Guanabara. Belo Horizonte. Ano 2006.

CORRER, Rinaldo. Deficiência e inclusão social: Construindo uma nova comunidade. Editora da universidade do sagrado coração. São Paulo. 2003.

DONALÍSIO, Maria Rita, GLASSER, Carmen Moreno. Vigilância entomológica e controle de vetores do Dengue. Rev. Bras. Epidemiologia. Vol. 5, N 3, ano 2002.

FACACCIO, Roberto. Tratando de Infectologia, vol. 1, editora Atheu. São Paulo, 2010.

FARIA, Evangelina Maria Brito de et.al. Língua portuguesa e LIBRAS: teorias e práticas 3. João Pessoa: Editora Universitária da UFPB, 2011.

KARNOPP, Lodenir. Literatura Surda. Curso de Licenciatura e Bacharelado em Letras-Libras na Modalidade a Distância. Universidade Federal de Santa Catarina, 2010.

Literatura Surda. Florianópolis, 2008.

LEÃO, Raimundo Nonato Queiroz. Doenças Infecciosas e Parasitárias- Enfoque Amazônico, editora Cejup, Belém - Pá, 1997.

LOIOLA, Carlos Pratão Prates. Dengue nas Américas. Simpósio sobre dengue. Universidade de São Paulo. Faculdade de Saúde Pública. 2000. p. 48-56.

NEVES, David Pereira. Parasitologia Humana, Editora Atheneu 10 Edição. São Paulo. 2003

QUADROS, Ronice Muller de. O tradutor e intérprete de língua brasileira de sinais e língua 
portuguesa: programa nacional de apoio à educação de surdos. Brasília, 2004.

SALLES, Heloisa Maria Moreira Lima. Ensino de Língua Portuguesa para surdos: Caminhos para a prática pedagógica. Vol. 1. Brasília. 2004.

SILVEIRA, Rosa Maria H. Texto e diferenças. In: Leitura em revista 03. Ano 02,

Janeiro-junho, 2002. p. 19-22.

SKLIAR, C. A surdez: um olhar sobre as diferenças. Porto Alegre. Mediação, 1998.

STOKOE, W. C./Casterline, D. C./Croneberg, C. G.(1976): A dictionary of American Sign language on inguistic principles.New Edition. Silver Spring, Md: Listok Press.

SUPALLA, T. Structure and acquisition of verbs of motion and location in American sign language. Ph. D. dissertation, University of california, San Diego.

TEIXEIRA, Maria da Glória; BARRETO, Maurício Lima; GUERRA, Zouraide. Epidemiologia e medidas de prevenção do Dengue. 1999, vol.8, n.4,

TONOZI-REIS, Marilia F. de C. Metodologia da pesquisa. Curitiba: IESDE, 2005.

VERONESI, Ricardo; Doenças Infecciosas e Parasitárias. Ed. 08. Editora Guanabara-Koogan, Rio de Janeiro 1991.

${ }^{[1]}$ Biólogo. Especialista Microbiologia. Especilista em Libras. Faculdade UNISABER.

${ }^{[2]}$ Especialista em Libras, Mestre em E. Matemática. Faculdade UNISABER.

${ }^{[3]}$ Biólogo. Doutor em Medicina/Doenças Tropicais. Docente e Pesquisador na Universidade Federal do Pará - UFPA.

\section{PUBLIQUE SEU ARTIGO CIENTÍFICO EM:}

https://www.nucleodoconhecimento.com.br/enviar-artigo-cientifico-para-submissao 